\title{
Process Standardization for Development and Quality Evaluation of Aromatic Black Rice Incorporated Idli
}

\begin{abstract}
Background: Black rice also known as purple rice which is rich in anthocyanin, antioxidants, fiber, minerals etc. are abundantly found in Manipur. Black rice is an underutilized crop in Manipur and most parts of North East India although it regarded as the super food. The objective of the present study is to develop Idli by blending the aromatic black rice (Poireiton), white rice (IR20) and black gram (Urad Dal).

Methods: The amount of black rice and IR20 are varied (5\%,10\%, 15\% and 20\%) keeping the black gram level at $33 \%$ of the total weight. The best combination of formulated Idli is selected by analyzing the variations in fermentation volume, $\mathrm{pH}$, colour values, sensory parameters and its overall acceptability. Sensory parameters of the developed idli are conducted by 9-point hedonic scale by 10 semi trained panel.

Result: The Idli with black rice level of $10 \%$ and $12 \mathrm{hrs}$ fermentation time has the highest overall acceptability in sensory evaluation. The best treatment of idli has a $\mathrm{pH}$ of 5.28 , increased in the volume batter as $140 \%$ and color values as $\mathrm{L}^{*}$, $\mathrm{a}^{*}$ and $\mathrm{b}^{*}$ as $58.42,5.92$ and 10.51 respectively.
\end{abstract}

Key words: Black rice, Fermentation time, Idli, Sensory evaluation, Volume.

\section{INTRODUCTION}

Idli, which is especially popular in South India, appeal as a breakfast food due to its spongy textural and organoleptic attributes (Susheelamma and Rao, 1974). As it has good amount of digestible protein and vitamins especially Bcomplex, it is consumed all over India by all types of people right from children to old, poor to rich because of its taste, flavour, aroma, nutritional and health benefits. Generally, fermentation process is carried out by Leuconostoc mesenteroides and Streptococcus faecalis, which are naturally present on the surface of the grains/legumes/ utensils. But sometimes fenugreek seeds being a rich source of amino acid are added to produce wild yeast in idli (Kumari and Dubey, 2012).

The main aim of fermentation in idli preparation is to provide leavening effect, typical flavour and improving the nutritional quality. A number of researches has been conducted on preparing certain novel idli or idli-like product by replacing cereal/legume including northern beans, soybeans Ohariya et al. (2017), millets Balasubramanium et al. (2006), whey based dal (Shukla and Dubey, 2014) but very few got succeed.

Black gram is the major contributor of protein content in idli, compared to rice. In idli, by virtue of its impressive soft and non-sticky textural property, IR20 variety of rice is most suitable over raw rice for producing idli, whereas black gram is used in decorticated dhal form. The soft and spongy texture of the idli is greatly influenced by the physicochemical characteristics of black grams. Black rice (Poireiton) has a very high content of total anthocyanin and antioxidants. It also has various health benefits because of
College of Food Technology, Central Agricultural University, Lamphelpat, Imphal West-795 004, Manipur, India.

Corresponding Author: Angam Raleng, College of Food Technology, Central Agricultural University, Lamphelpat, Imphal West-795 004, Manipur, India. Email: angamraleng@gmail.com

How to cite this article: Angam Raleng, Bhavesh Datla, Rebika Salam (2021). Process Standardization for Development and Quality Evaluation of Aromatic Black Rice Incorporated Idli. Asian Journal of Dairy and Food Research. DOI: 10.18805/ajdfr.DR-1729. Submitted: 24-05-2021 Accepted:24-06-2021 Online: 02-08-2021

the high content of phenolic compounds as compared to other black rice varieties (Thanuja and Parimalavalli, 2018).

The uniqueness of the black aromatic rice of Manipur is its pleasant aroma and color coupled with stickiness which is not common in other black rice grown in other parts of the world. The local name of this black rice is Chak-hao. Black rice owes its color to powerful natural black coloring pigments called anthocyanins which boost an impressive antioxidant activity adding to health benefits of this rice variety. It also consists of pharmacological compounds such as $\gamma$-oryzanol, phenolic and flavonoid compounds Balasubramaniam et al. (2019). The available literature revealed that there is wide scope and advantages of utilisation of black rice in the daily diet.

The present study aims to standardize the level of black rice and the white rice in idli and also the fermentation time of black rice-based idli. This study also aims to evaluate the sensory qualities of the developed product as affected by the level of the black rice incorporated as well as the fermentation time. 


\section{MATERIALS AND METHODS}

This chapter deals with the description of various materials and methods used to accomplish the experimental work done to attain the desired objectives of the study entitled "Process Standardization for Development and Quality Evaluation of Aromatic Black Rice Incorporated Idli”. The experimental studies were carried out in the month of July, 2019 in the College of Food Technology, Lamphelpat, Central Agricultural University, Imphal, Manipur, India. The methodology adopted has been described under the following headings.

\section{Procurement of raw materials}

A black gram (Urad dal) and black rice (Poireiton) and white rice (IR 20) were procured from local market of Imphal, Manipur. The ingredients for the development of the Black rice Idli can be seen from the Fig 1.

\section{Black gram}

Black gram (Phaseolus mungo Roxb.) is a black lentil, commercially sold as Urad Dal. Due to the presence of polysaccharides, it plays the leading role in the fermentation of batter. Some producers also used soybean, green gram and Bengal gram. It also adds to the protein requirement. The nutrition value of Black gram is highlighted in the Table 1.

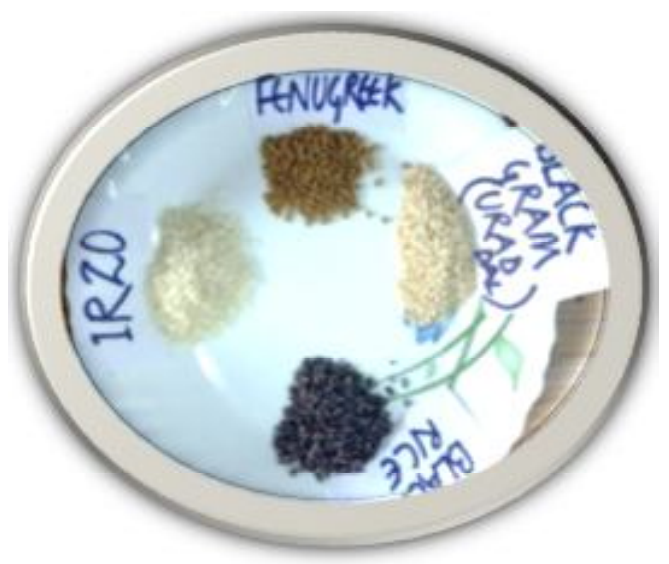

Fig 1: Raw material (Black rice, IR 20 rice, Black gram, Fenugreek).

\section{Black rice}

Polished black rice (Poireiton) is used for making idli. Due to the high protein content in black rice, fermentation volume is increased and also it imparts a characteristic flavor and color. The approximate nutrition value of Black rice (Poireiton) is given in the Table 1.

\section{IR20}

Rice (Oryza sativa) is used for giving the creamy white appearance, IR20 rice is used for providing nonstick batter, which is present in raw rice. It is the primary source of energy. The nutrition value of IR20 can be seen in the Table 1.

\section{Fenugreek}

Trigonella foenum-graecum is an annual plant in the family Fabaceae with leaves consisting of three smalls obviate to oblong leaflets. Fenugreek seeds draw the same type of wild yeast as the black gram. In the traditional method, the seeds are put in the rice pan so that both the pans (black gram, as well as the Rice) will draw wild yeast.

Four treatments were made for four different compositions of batter and were replicated based on fermentation time as shown in Table 2. The samples were shown in Fig 1.

Table 1: Nutritional value of IR20, black rice and black gram.

\begin{tabular}{lccc}
\hline Parameters & $\begin{array}{c}\text { Black gram } \\
(\mathrm{gm} / 100 \mathrm{gm})\end{array}$ & $\begin{array}{c}\text { Black rice } \\
\text { (Poiretion) } \\
(\mathrm{gm} / 100 \mathrm{gm})\end{array}$ & $\begin{array}{c}\text { IR20 } \\
(\mathrm{gm} / 100 \mathrm{gm})\end{array}$ \\
\hline Carbohydrate & 65.8 & 69.55 & 84.00 \\
Protein & 24.16 & 10.80 & 06.46 \\
Starch & 52.00 & 79.82 & 79.5 \\
Fat & 0.87 & 0.83 & 0.27 \\
Amylose content & 17.00 & 20.60 & 32.00 \\
\hline
\end{tabular}

*Source: [1] Value addition of idli through incorporation of greens and legumes, Uma Maheswari S (2014) Pondicherry University. [2] Wadbok Rani (2018). Grain Quality Characterization and Molecular Diversity Analysis of Aromatic Rice (Oryza Sativa L.), Central Agricultural University, Imphal.

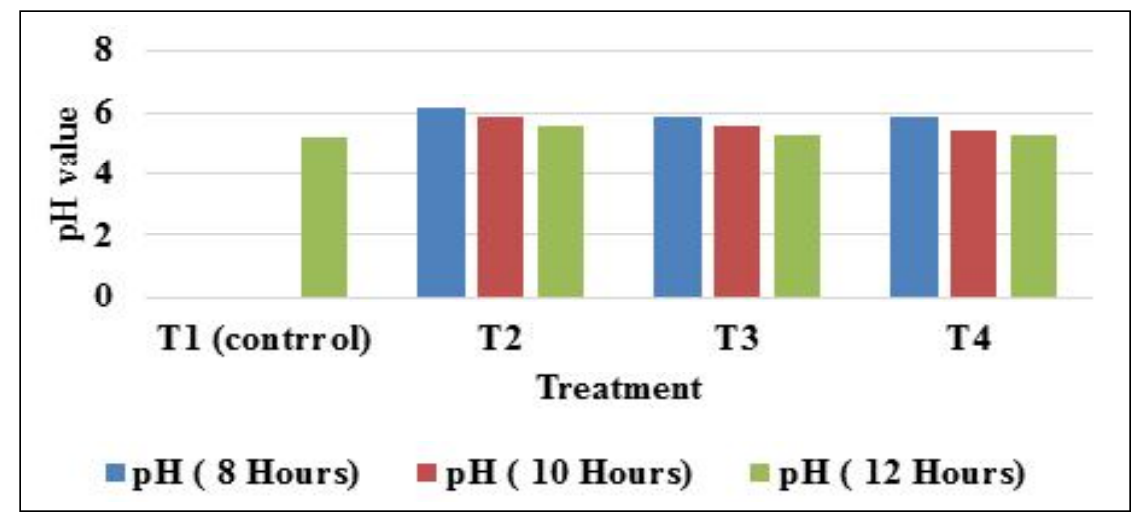

Fig 2: Effect of black rice and fermentation time on $\mathrm{pH}$ of the idli batter. 


\section{Moisture content analysis for raw materials}

The moisture content of the raw materials was determined by the AOAC (2002) method. A $3 g$ of each sample was taken in Petri plates with initial blank weight of dried cleaned petri dish. The samples were kept in oven at $105^{\circ} \mathrm{C}$ and the weight of the dish is measured after 3 hours.

\section{$\mathrm{pH}$, volume of batter and density of batter}

The $\mathrm{pH}$ of the primary batter sample was measured using $\mathrm{pH}$ meter (WTW Inolab 720) after thoroughly mixing of the sample. Temperature was maintained at $35^{\circ} \mathrm{C}$ whole thorough the fermentation process using incubator. For each treatment, three different fermentation times were selected i.e., 8 hours, 10 hours and 12 hours. The volume of batter was measured by putting the batter in a measuring cylinder and initial and final volume after fermentation was recorded. The volume was recorded after the samples were taken out from the incubator at 8, 10, 12 hours with the help of a measuring cylinder. The difference in volume recorded was volume increased by fermentation. For measuring a change in density, the weight of batter placed is divided by change in volume.

\section{Preparation of Idli}

The parboiled IR20 rice (102-122g), polished black rice (8$30 \mathrm{~g}$ ) and decorticated black gram (66g) (Urad dal) were weighed and soaked in $150 \mathrm{ml}$ of water separately, soaking was done for $5 \mathrm{hrs}$ and water was drained and the soaked grains were ground together in wet grinder by adding required quantity of residual water while grinding to maintain the consistency and for effective grinding. Fenugreek and

Table 2: Treatments used in the development of the black rice incorporated Idli.

\begin{tabular}{lccc}
\hline Treatment & IR20 & Black gram & $\begin{array}{c}\text { Black rice } \\
\text { (Poireiton) }\end{array}$ \\
\hline T1 & $66 \%$ & $33 \%$ & $0 \%$ \\
T2 & $61 \%$ & $33 \%$ & $5 \%$ \\
T3 & $56 \%$ & $33 \%$ & $10 \%$ \\
T4 & $51 \%$ & $33 \%$ & $15 \%$ \\
\hline
\end{tabular}

salt ( $30 \mathrm{~g}$ and $2 \mathrm{~g}$ respectively) were added at the time of grinding. Control and composite batters were kept in an incubator (Model: NSW-151 WJ) and were allowed to ferment at an incubation temperature of 35! for 12-14 hours. After completion of natural fermentation, batters were thoroughly mixed and salt was added for stopping fermentation and providing salty flavor to the idli. Idli pans were oiled so that steamed idli will not stick to the pan can be removed easily. The batters were then poured into idli steamer cups and were steamed for 18 mins to get the final steamed idli.

\section{Color measurement}

Color of the developed product was evaluated using Hunter Lab color flex (Model Dp-9000 D25A). Samples were scanned to determine lightness $\left(\mathrm{L}^{*}\right)$, red-green $\left(\mathrm{a}^{*}\right)$ and yellow-blue $\left(b^{*}\right)$ color components. $L^{*}$ is a measure of the brightness from black (0) to white (100). Parameter $a^{*}$ describes red-green color with positive values indicating redness and negative values indicating greenness. Parameter $b^{*}$ describes yellow-blue color with positive values indicating yellowness and negative values indicating blueness. The color of each sample was measured in triplicate and average color of idli was calculated.

\section{Sensory evaluation of the Idli}

Idli prepared with different combination of black rice, white rice and black gram were subjected to sensory evaluation on a 9-point Hedonic scale for five parameters viz. color and appearance, taste and aroma, texture, fluffiness and overall acceptability. The 10 semi trained panelists were asked to give score according to their likes and dislikes based on the scale. The scores for all the attributes were tabulated and the mean values were calculated. These mean scores represented the panel judgment about quality of the sample and selection of the best sample on the basis of overall acceptability.

\section{Statistical analysis}

The data obtained from the experiment was subjected to Two Way Analysis of Variance (ANOVA) to see if there was

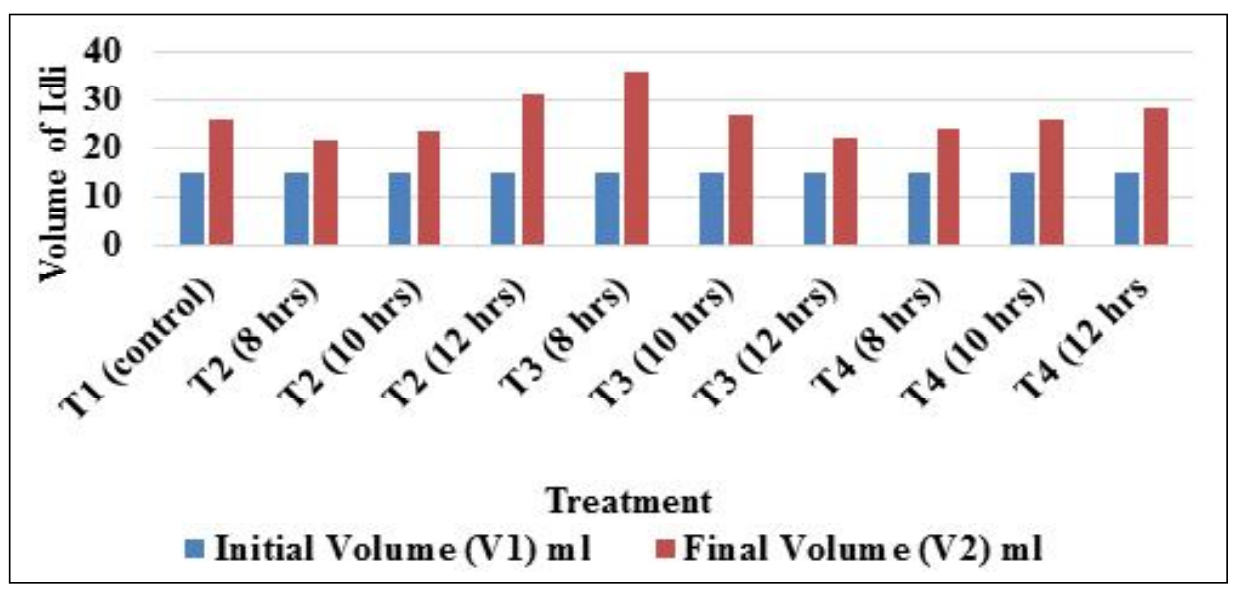

Fig 3: Effect of black rice and fermentation time on volume of the idli batter. 
statistical difference among different combinations of white rice, black rice and black gram on volumetric increase, $\mathrm{pH}$, colour attributes and overall acceptability of idli at $5 \%$ level of significance using MS Excel 2013.

\section{RESULTS AND DISCUSSION}

The black rice idli incorporated with white rice (IR20) and Black gram with different treatments is developed. And the best two samples developed from the different treatments (Table 2) are shown in the Fig 6 and Fig 7.

\section{Moisture content analysis}

After taking the average final weight and difference, the average moisture content of IR 20 , black rice and black gram were found to be $8.67 \%, 11.57 \%$ and $9.67 \%$ respectively.

\section{Effect of black rice and fermentation time on $\mathrm{pH}$ of the} idli batter

The $\mathrm{pH}$ is an important parameter in idli because the taste of the idli is a little sour, which the consumer enjoys. Due to fermentation, the $\mathrm{pH}$ of the batter decreased because of the production of lactic acid due to lactic acid fermentation by $L A B$ bacteria. The $\mathrm{pH}$ ranged from 5.28 to 6.12 . Statistical analysis indicated that the level of BR (black rice) and fermentation time have significant effect at $5 \%$ level of significant $(\mathrm{p}<0.05)$ on $\mathrm{pH}$ of the product which can be seen in Fig 2.

\section{Effect of black rice and fermentation time on volume of} the idli batter

The fermentation volume is an indication as to how the idli prepared will have the texture in terms of its expansion or the fluffiness of the idli prepared. It is an important parameter in making of the idli because the consumer tends to like the fluffy texture of the idli. The increased in volume of the idli batter ranged from $70.94 \mathrm{ml}$ to $100.5 \mathrm{ml}$. It can be seen from the Table 3 that the volume of the batter increased with the increase in the fermentation time but decreased with the increase in the level of the BR. Statistical analysis for volume increased showed that fermentation time and level of BR has significant effect at $5 \%$ level of significant $(p<0.05)$ on volume increased of the idli batter. A steady decrease in firmness was observed throughout the fermentation, probably due to the corresponding increase in moisture (Fig 3). Microbial gas production, increased moisture and decreased density of batter are responsible for the variations in texture.

\section{Effect of black rice and fermentation time on Color parameters}

The color values " $L$ " and "b" decreases with the increase in fermentation time and the level of BR from 73.80 to 53.71 and 16.46 to 8.85 respectively (Table 3 ), whereas color value "a" increased with the increase in fermentation time and level of BR from 2.18 to 6.89 . Statistical analysis for color values showed that fermentation time and level of BR has significant effect at $5 \%$ level of significant $(p<0.05)$ on color value " $L$ " but on color value " $b$ " there was no significant difference observed. However, significant reduction in " $L$ " and " $b$ " values and increase in "a" value was observed for idli at $15 \%$ level of BR and 12 hours of fermentation time as shown in Fig 4, the values shows that the major changes in color occurred in color values when both the level of BR and the fermentation time were increased. The decrease in L-value with level of BR and fermentation time may be attributed to darkening induced with the increased in the level of BR incorporated in the treatment. Similarly, with the increase in level of BR and the fermentation time, a-value increases

Table 3: Effect of black rice and fermentation time on quality parameters of Idli.

\begin{tabular}{|c|c|c|c|c|c|}
\hline \multirow{2}{*}{ Parameter } & \multirow{2}{*}{$\begin{array}{c}\text { Black rice } \\
(\%)\end{array}$} & \multicolumn{3}{|c|}{ Fermentation time(hours) } & \multirow{2}{*}{ Statistical $p$ values } \\
\hline & & 8 & 10 & 12 & \\
\hline \multirow[t]{3}{*}{ Volume increase } & 5 & $80.87 \pm 0.16$ & $89.7 \pm 0.11$ & $100.5 \pm 0.14$ & Black rice $(\%) \sigma=0.035124$ \\
\hline & 10 & $73.33 \pm 0.08$ & $85.4 \pm 0.04$ & $97.66 \pm 0.06$ & Fermentation time $\sigma=0.00204$ \\
\hline & 15 & $70.94 \pm 0.10$ & $82.4 \pm 0.13$ & $93.34 \pm 0.04$ & \\
\hline \multirow[t]{3}{*}{$\mathrm{pH}$} & 5 & $6.12 \pm 0.31$ & $5.82 \pm 0.20$ & $5.56 \pm 0.24$ & Black rice $(\%) \sigma=0.017241$ \\
\hline & 10 & $5.89 \pm 0.46$ & $5.54 \pm 0.21$ & $5.32 \pm 0.56$ & Fermentation time $\sigma=0.02139$ \\
\hline & 15 & $5.82 \pm 0.71$ & $5.41 \pm 0.21$ & $5.28 \pm 0.54$ & \\
\hline \multirow[t]{3}{*}{ Color-L* } & 5 & $65.21 \pm 0.12$ & $64.53 \pm 0.19$ & $63.36 \pm 0.06$ & Black rice $(\%) \sigma=0.032104$ \\
\hline & 10 & $64.55 \pm 0.11$ & $63.88 \pm 0.20$ & $62.72 \pm 0.05$ & Fermentation time $\sigma=0.04834 \mathrm{C}$ \\
\hline & 15 & $63.95 \pm 0.11$ & $63.17 \pm 0.21$ & $61.99 \pm 0.05$ & \\
\hline \multirow[t]{3}{*}{ Color-a* } & 5 & $3.51 \pm 0.05$ & $3.64 \pm 0.11$ & $3.86 \pm 0.51$ & Black rice $(\%) \sigma=0.65310$ \\
\hline & 10 & $5.65 \pm 0.06$ & $5.72 \pm 0.10$ & $5.92 \pm 0.49$ & Fermentation time $\sigma=0.97501 \mathrm{~s}$ \\
\hline & 15 & $7.42 \pm 0.05$ & $7.64 \pm 0.11$ & $7.89 \pm 0.50$ & \\
\hline \multirow[t]{3}{*}{ Color-b* } & 5 & $19.31 \pm 0.09$ & $18.98 \pm 0.11$ & $18.46 \pm 0.06$ & Black rice $(\%) \sigma=0.754310$ \\
\hline & 10 & $11.36 \pm 0.07$ & $11.23 \pm 0.12$ & $10.51 \pm 0.07$ & Fermentation time $\sigma=0.981172$ \\
\hline & 15 & $9.61 \pm 0.06$ & $9.07 \pm 0.11$ & $8.85 \pm 0.05$ & \\
\hline \multirow[t]{3}{*}{ Overall Acceptability } & 5 & $6.29 \pm 0.56$ & $6.52 \pm 0.56$ & $6.78 \pm 0.91$ & Black rice $(\%) \sigma=0.015312$ \\
\hline & 10 & $6.49 \pm 1.10$ & $6.65 \pm 0.93$ & $7.48 \pm 0.54$ & Fermentation time $\sigma=0.02459$ \\
\hline & 15 & $6.35 \pm 0.57$ & $6.72 \pm 0.55$ & $6.96 \pm 0.90$ & \\
\hline
\end{tabular}




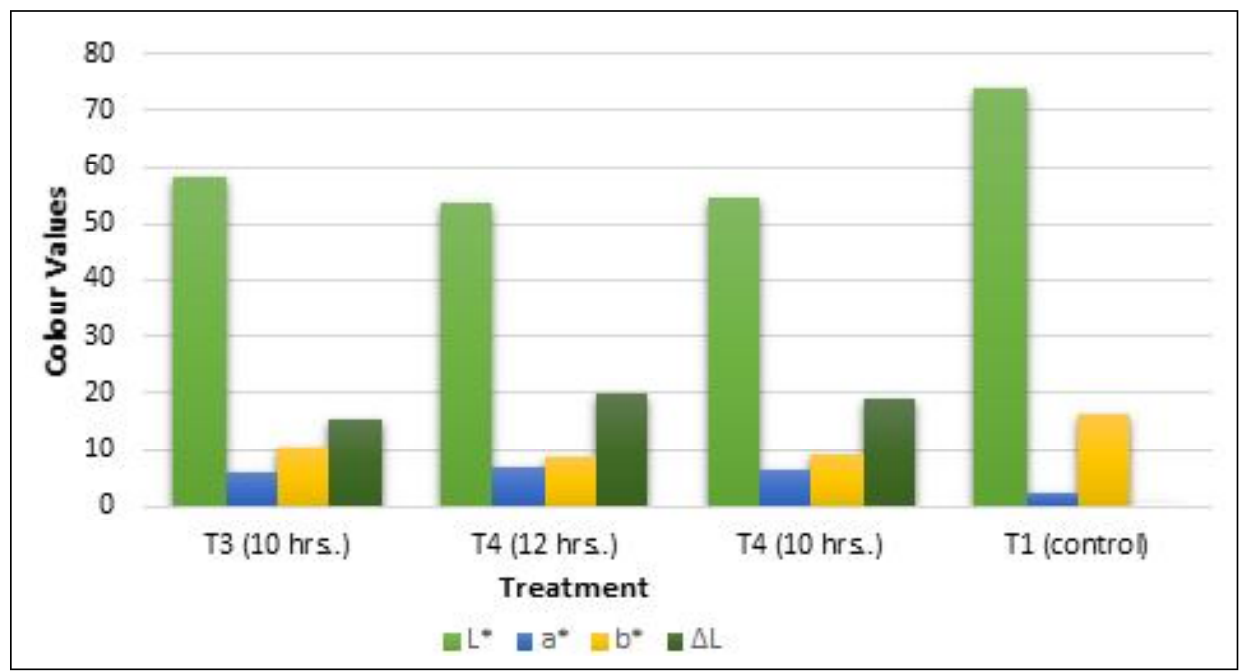

Fig 4: Effect of black rice and fermentation time on color parameters of the idli.

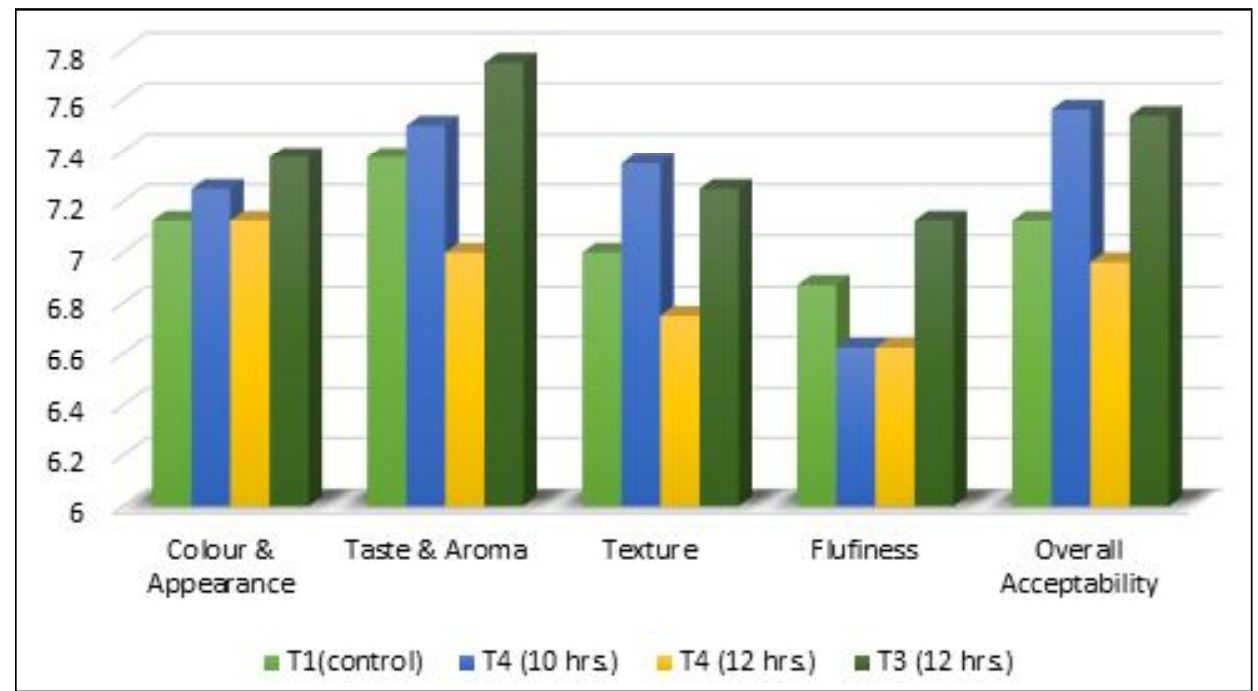

Fig 5: Effect of black rice and fermentation time on sensory parameters of the idli.

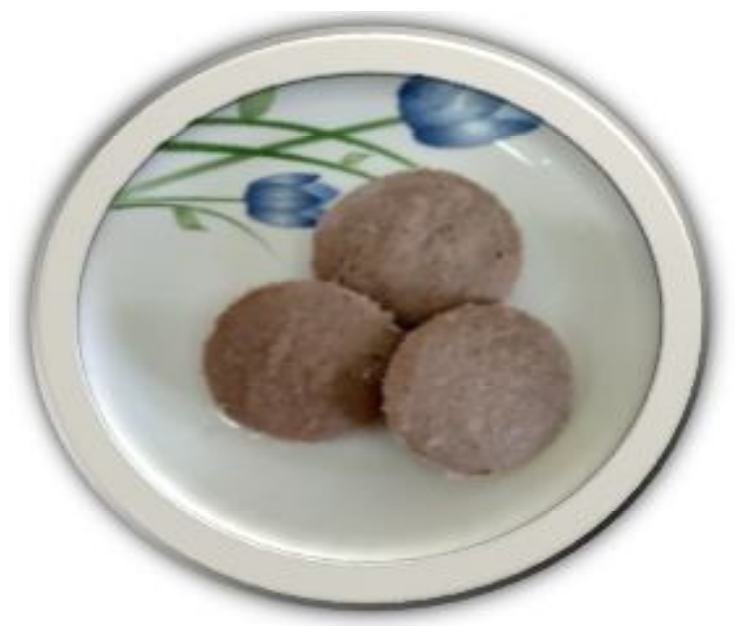

Fig 6: Treatment $\mathrm{T}_{3}(12 \mathrm{hrs})$.

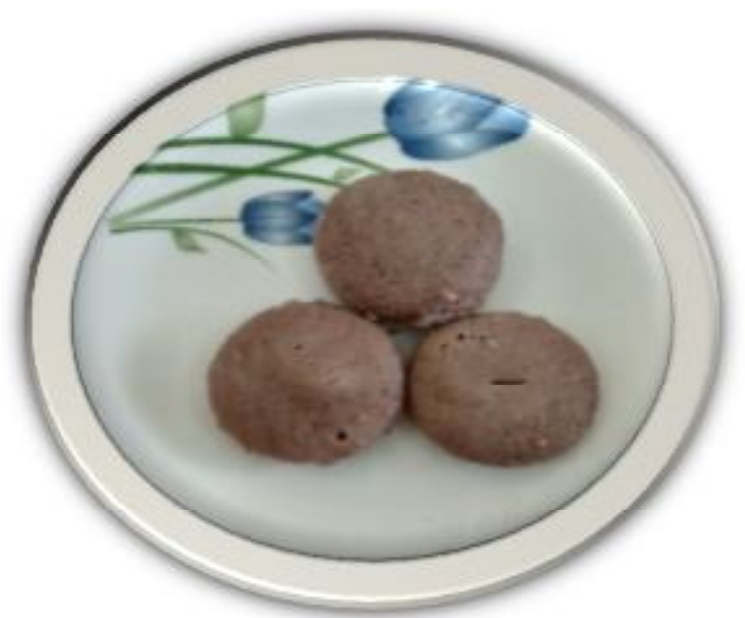

Fig 7: Treatment $\mathrm{T}_{4}(10 \mathrm{hrs})$. 
with may be attributed to the redness developed due to the pigmentation of the BR. The increased in a-value with the level of BR and the fermentation time may be attributed to the action of Lactobacillus because it has tendency of making color compound to colorless, which is because of the difference in fermentation time.

\section{Effect of black rice and fermentation time on sensory parameters}

The overall acceptability (OA) of the idli is the score given by the 10 semi trained panel after being analyzed for color and appearance, taste and aroma, texture and fluffiness of the idli in sensory analysis. Similar study was conducted by Shruti and Brijlata (2014). It was observed that the overall acceptability of idli ranged from 6.96 to 7.68 . It can also be observed from the Table 3 that the Overall acceptability of the idli increased with the increase in both the level of the BR and the fermentation time with product at $10 \% \mathrm{BR}$ and 12 hours fermentation time. Also statistical analysis indicated that the level of BR and fermentation time have significant effect on overall acceptability of the product which can be seen in Fig 5. Acceptability of the product despite of the change in color was may be due to the fluffiness and the aroma of the black rice and the perception of panelist indicates that the color was within permissible limit.

\section{CONCLUSION}

Black rice-based idli product incorporated to pulses is highly popular in India as well in other parts of the world. The idli produced by black rice ranged of $5-15 \%$ (Fig 7) indicated that the fermentation time has significant effect on quality characteristics of black rice idli. The sensory studies revealed that black rice + white rice + black gram powder developed idli produced showed a significant changes in quality and Overall acceptability of the developed black rice idli. The quality parameters in the sensory studies signifies and suggest that the developed BR idli are fit for consumption by all levels of community as the panel consists of a heterogeneous group of community from all the parts of India.

\section{REFERENCES}

Balasubramaniam, J.P, Pazhaniyandi, S.S. and Rengaraj, S. (2019). Health benefits of black rice - A review. Grain and Oil Science and Technology. 2: 109-113

Balasubramanium, S., Singh N., Ilys, S.M. and Wanjari, O.D. (2006). Effect of selected decorticated legumes protein on rheology of maize extrudate pastes. Journal of Food Science and Technology. 43: 590-594.

Kumari, P. and Dubey, P. (2012). Effect of fenugreek seeds flour blending on sensory and chemical characteristics of semolina idli. International Journal of Current Research and Review. 04(23): 95-99.

Ohariya, P., Singh, A., Rajput, L.P.S. (2017). Quality attributes of instant kodo-soy idli mix as affected by fermentation period. International Journal of Conservation Science. 5: 1611-1615.

Shukla, S. and Dubey, B. (2014). Development of Idli using whey based Dhal-rice blend. Asian Journal of Dairy and Food Research. 33(3): 215-220.

Susheelamma, N.S. and Rao, M.V.L. (1974). Surface active principle in black gram (Phaseolus mungo) and its role in the texture of leavened foods containing the legume. Science of Food and Agriculture. 25(6): 665-673.

Thanuja, B. and Parimalavalli (2018). Role of black rice in health and diseases. International Journal of Health Sciences and Research. 8(2): 241-248.

Uma, M.S. (2014). Value addition of idli through incorporation of greens and legumes. Department of Food Science and Technology, School of Life Sciences, Pondicherry University, Puducherry.

Wadbok, R. (2018). Grain quality characterization and molecular diversity analysis of aromatic rice (Oryza Sativa L.) genotype using SSR markers, M.Sc. Thesis Barapani, School of Crop Improvement, CPGS, Barapani, Central Agricultural University, Imphal. 